\title{
Pituitary Volumes Are Reduced in Patients with Somatization Disorder
}

\author{
Hanefi Yildirim¹, Murad Atmaca ${ }^{2}{ }^{凶}$ Burcu Sirlier $^{2}$ and Alperen Kayali ${ }^{1}$ \\ ${ }^{1}$ Department of Radiology, Firat University School of Medicine, Elazig, Turkey \\ ${ }^{2}$ Department of Psychiatry, Firat University School of Medicine, Elazig, Turkey
}

Objective Despite of the suggested physiological relationship between somatoform disorder and disturbances in HPA axis function no volumetric study of pituitary volumes in somatization disorder has been carried out. Therefore, we aimed to use structural MRI to evaluate the pituitary volumes of the patients with somatization disorder.

Methods Eighteen female patients with somatization disorder according to DSM-IV and same number of healthy controls were included into the study. All subjects were scanned using a 1.5-T General Electric (GE; Milwaukee, USA) scanner. Pituitary volume measurements were determined by using manually tracings according to standard antomical atlases.

Results It was found significantly smaller pituitary volumes of the whole group of somatization patients compared to healthy ( $\mathrm{t}=-$ $3.604, \mathrm{p}=0.001)$. ANCOVA predicting pituitary volumes demonstrated a significant main effect of diagnostic group $(\mathrm{F}=13.530, \mathrm{p}<0.001)$ but TBV $(\mathrm{F}=1.924, \mathrm{p}>0.05)$ or age $(\mathrm{F}=1.159, \mathrm{p}>0.05)$. It was determined that there was no significant correlation between smaller pituitary volumes and the duration of illness $(r=0.16, \mathrm{p}>0.05)$ in the patient group.

Conclusion In conclusion, we suggest that the patients with somatization disorder might have significantly smaller pituitary volumes compared to healthy control subjects.

Psychiatry Investig 2012;9:278-282

Key Words Somatization disorder, MRI, Pituitary, Volume.

\section{INTRODUCTION}

Somatization disorder is one of the somatoform disorders and is characterized by a lot of physical complaints in a variety of organ systems that occurs over a period of several years beginning before 30 years old and results in treatment being sought or significant impairment in social, occupational, or other important areas of the functioning. ${ }^{1}$ Somatization disorder is encountered in females compared to males, with a lifetime prevalence rates of varying from 0.2 to 2 percent for females, and less than 0.2 percent for males. ${ }^{2,3}$ In our medicine practice, it has been observed that these patients frequently make the primary care units occuped. In their study

Received: August 12, 2011 Revised: January 2, 2012

Accepted: May 29, 2012 Available online: September 6, 2012

$\triangle$ Correspondence: Murad Atmaca, MD

Firat (Euphrates) Universitesi, Firat Tip Merkezi, Psikiyatri Anabilim Dali, 23119 Elazig, Turkey

Tel: +90-424-233-3555/2282, Fax: +90-424-238-7688

E-mail: matmaca_p@yahoo.com

@ This is an Open Access article distributed under the terms of the Creative Commons Attribution Non-Commercial License (http://creativecommons.org/licenses/bync/3.0) which permits unrestricted non-commercial use, distribution, and reproduction in any medium, provided the original work is properly cited. to assess the extent of the overlap of somatization with other psychiatric disorders and to compare the medical utilization of somatizing and nonsomatizing patients, Barsky et al. ${ }^{4}$ reported that patients with somatization had approximately twice the outpatient and inpatient medical care utilization and twice the annual medical care costs of nonsomatizing patients.

Mind-brain relationship in the etiopathogenesis of psychopathology came from Freud himself. ${ }^{5}$ Kat $^{6}$ proposed a model of 5-HT function involving the routine filtering and suppression of violent or libidinal impulses which appeared to resemble Freud's model of ego-id interactions at least in part, suggesting that it might be possible to psychobiologically substantiate a Freudian metaphor. Recently, in their review summarizing psychobiological studies including patients with depression and/or somatization-associated syndromes, Rief et al. ${ }^{7}$ reported that many psychobiological pathways acted differently in depression and somatization. Despite of the knowledge above, somatoform disorders including somatization disorder are in infancy in regard to brain investigations that aim to find spesific regions accounting for the pathophysiology of these disorders. In one of the limited contributions, Vu- 
illeumier et al. ${ }^{8}$ examined seven patients with conversion disorder using by single photon emission computerized tomography using ${ }^{99 \mathrm{~m}} \mathrm{Tc}-\mathrm{ECD}$ and revealed a decrease of regional cerebral blood flow in the thalamus and basal ganglia contralateral to the deficit and suggested that hysterical conversion deficits might entail a functional disorder in striatothalamocortical circuits controlling sensorimotor function and voluntary motor behaviour. Stern ${ }^{9}$ found an association between conversion symptoms and right hemisphere because of the fact symptoms are more frequent on left side limbs. Furthermore, it was reported some neurophysiological abnormalities $^{10-12}$ and neuropsychological findings ${ }^{13}$ in patients with hysterical conversion. We previously performed a morphometric MRI study to compare regional brain volumes in ten women with conversion disorder (CD) and same number of healthy comparison subjects and found the patients with CD had significantly smaller mean volumes of the left caudate nucleus, lentiform nucleus and right caudate nucleus, lentiform nucleus and thalamus compared to healthy controls. ${ }^{14}$ We aimed to volumetrically evaluate the orbito-frontal cortex (OFC), anterior cingulate, caudate nucleus, and thalamus of the patients with hypochondriasis, another somatoform disorder in our another study ${ }^{15}$ and found that hypochondriac patients had significantly smaller mean left and right OFC, and greater left but not right thalamus volumes compared with healthy controls. On the other hand, we examined the hippocampus amygdalar complex which are associated with both stress and regulation of emotion that are main basis clinical presentation of somatization disorder in the patients with somatization disorder and found that in regard to unadjusted mean volumes of measured structures, the patients had significantly smaller mean volumes of the left and right amygdala. ${ }^{16}$

It has been well-established that hippocampo-amygdalar complex is a glucocorticoid feedback area, is highly sensitive to endogenous glucocorticoid levels and so is an important region affected by stress modulation organized by the hypothalamo-pituitary-adrenal axis (HPA), ${ }^{17-19}$ an important axis in anxiety and fear is well established. Under stress, hypothalamic corticotropin-releasing hormone $(\mathrm{CRH})$ production rises, stimulating the pituitary release of adrenocorticotropin hormone (ACTH). Consequently, cortisol secretion by the adrenal cortex increases. In the etiology of somatoform disorders, multifactorial approach including physiological, psychological, and social contributions has been proposed. ${ }^{20}$ When we deal with the physiological mechanisms, one of the important contribution comes from the function of the HPA because of the fact that hypocortisolism has been suggested to cause a vulnerability for the occurrence of somatoform symptoms. ${ }^{21}$ On the other hand, it was reported that increased
HPA activity leading to high cortisol values might affect pituitary volume. ${ }^{22}$ Thus, in the present study, we consider that dysregulated HPA axis might have affected the pituitary volumes in somatization patients. In this context, we previously examined the pituitary volumes in patients with hypochondriasis. ${ }^{11}$ Twenty individuals with hypochondriasis (ten males, ten females), aged 20 to 48 years, and healthy controls were included into that study. We found significantly smaller pituitary volumes of the whole group of hypochondriac patients compared to healthy controls [age and ICV (intracranial volume) as covariates] and suggested that finding could be the keystone to a better understanding of the neurobiological basis of hypochondriasis.

Among the somatoform disorders, hypochondriasis is only disorder in which pituaitary volumes were evaluated. In somatization disorder, despite of the physiological relationship, no volumetric study regarding pituitary volumes has been. In this context, in the present study, we planned to examine pituitary volumes in the patients with somatization disorder who were selected among the patients included in our another study. ${ }^{16}$

\section{METHODS}

\section{Subjects}

We studied eighteen female patients with age range of 18 and 65 years who were recruited from the Firat University School of Medicine Department of Psychiatry. They were selected among the patients included in our another study, based on the re-evaluation of the same MRI scans. ${ }^{16}$ When we planned the present study, we tried to access the patients to obtain written informed consent for this new investigation. Two patients were not accessible. So, we excluded them from this analysis. All had already met DSM-IV criteria for somatization disorder by using the Structured Clinical Interview for DSM-IV ${ }^{23}$ and eighteen female healthy controls who were right-handed. The clinical interviews were administered by a psychiatrist (B.S.) who was blind to MRI data of the patients and controls. The mean $( \pm$ SD) age of the patients was $42.27 \pm$ 7.35 years while that of the controls was $40.61 \pm 3.58$ years. The subjects were excluded if they had any current or lifetime neurologic problems, endocrinological problems, the use of pharmacological treatments commonly used in endocrinology, a history of treatments with a potential effect on hypophyseal function, current severe medical problems, mental retardation, any problem that prevent them to suffer neuroimaging, or alcohol/substance abuse within the 6 months preceding the study. The patients had a history of previous following psychotropic treatments, antidepressants $(n=8)$, antipsychotics $(n=5)$ and anxiolytics $(n=10)$, though we did not include 
the patients who took any psychotropic drug within two weeks. It was not allowed the comorbidities excluding deprressive disorder which is most important comorbidity in somatization disorder. Healthy control subjects had no DSM-IV Axis I disorders in self or in a first-degree relative, as determined by the SCID non-patient version, no current medical problems, endocrinologic, neurologic or psychiatric histories, and no use of psychoactive medication within 2 weeks of the study. Hamilton Depression Rating Scale (HDRS) were administered to all subjects. ${ }^{24}$

\section{MRI procedure}

After signing an informed consent, all subjects were scanned using a 1.5-T General Electric (GE; Milwaukee, USA) scanner. Eight channel head coil was used. A high-resolution structural T1-weighted image was obtained using sagittally acquired 3D spiral fast spin echo high-resolution images [repetition time (TR) $=2,000 \mathrm{~ms}$, echo time $(\mathrm{TE})=15.6 \mathrm{~ms}$, field of view $(\mathrm{FOV})=240 \mathrm{~mm}$, flip angle $=20^{\circ}$, bandwidth $=20.8$, slice thickness $=2.4 \mathrm{~mm}$, echo spacing $=15.6 \mathrm{~ms}, 8$ echoes, matrix size $=240$, resolution $=0.9375 \times 0.9375 \times 2.4 \mathrm{~mm}]$.

The measurements were performed on a computer advanced workstation with the GE Volume Viewer voxtool 4.2 program. Tracing was performed by two researchers (HY, AK) blind to subject diagnosis. Boundary definition and the method of tracing the pituitary were performed by using standard neuroanatomical atlases ${ }^{25,26}$ with methods and definitions adapted from neuroimaging studies on the pituit$\operatorname{ary}^{27,28}$ and followed by MacMaster et al..$^{29}$ The superior border of the structure was described as the optic chiasm and infundibular recess of the third ventricle. The inferior border was the sphenoid sinus. Examples of the structure are presented in Figuer 1. All volumes were reported in cubic centi-

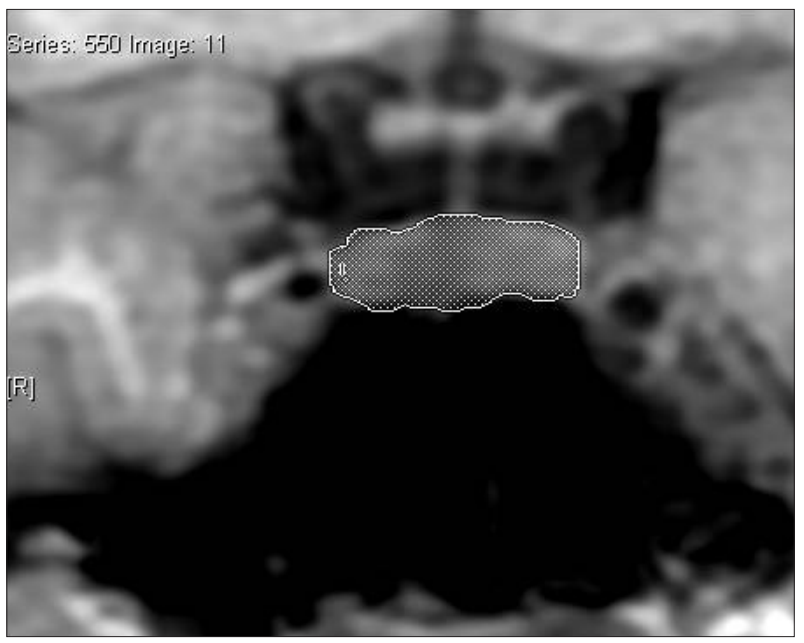

Figure 1. Anatomic landmarks for the tracing of the structures evaluated. meters. All measurements were made by well-trained and reliable raters (HY, $\mathrm{AK})$. The interrater ( $\mathrm{HY}, \mathrm{AK}$ ) and intrarater reliabilities for pituitary were enough $(0.90$ and 0.92 for pituitary, 0.88 and 0.94 for total white matter, and 0.90 and 0.94 for total gray matter).

\section{Statistical analysis}

Analysis of covariance (ANCOVA), t-test, Chi-square and Spearman's correlation analyses were conducted using SPSS for Windows software, version 13.0 (SPSS, Chicago, IL). In ANCOVA analyses, while age and total brain volume (TBV) were covariates, diagnosis and gender were used as between subject factors. Correlation analyses were done by using Spearman's rank test. Statistical significance was defined as $p<0.05$ by a two-tailed test.

\section{RESULTS}

In regard to age (mean age $\pm S D=42.27 \pm 7.35$ years for the patients and mean age $\pm \mathrm{SD}=40.61 \pm 3.58$ years for controls), education, gender (exactly same compositions) and handedness, there were no significant differences between the groups on comparisons ( $p>0.05)$. The mean HDRS scores the patients and controls were $15.89 \pm 3.05$ and $7.94 \pm 1.98(\mathrm{p}<0.001)$ (Table 1).

As can be seen in Table 1, it was found significantly smaller pituitary volumes of the whole group of somatization patients compared to healthy $(\mathrm{t}=-3.604, \mathrm{p}=0.001)$. ANCOVA predicting pituitary volumes demonstrated a significant main effect of diagnostic group $(\mathrm{F}=13.530, \mathrm{p}<0.001)$ but TBV $(\mathrm{F}=1.924$, $\mathrm{p}>0.05)$, age $(\mathrm{F}=1.159, \mathrm{p}>0.05)$, or HDRS $(\mathrm{F}=0.854, \mathrm{p}>0.05)$.

It was determined that there was no significant correlation between smaller pituitary volumes and the duration of illness $(r=0.16, p>0.05)$ in the patient group. Also, there is no correlative relation between pituitary volumes and depression, as

Table 1. Pituiatry volumes in patients with somatization disorder against control subjects

\begin{tabular}{lccc}
\hline & $\begin{array}{c}\text { Somatization } \\
\text { patients }(\mathrm{N}=18)\end{array}$ & $\begin{array}{c}\text { Helthy } \\
\text { subjects }(\mathrm{N}=18)\end{array}$ & $\mathrm{p}$ \\
\hline Age (years) & $42.27 \pm 7.35$ & $40.61 \pm 3.58$ & $>0.05$ \\
Gender (F/M) & $20 / 0$ & $20 / 0$ & $>0.05$ \\
HDRS scores & $15.89 \pm 3.05$ & $7.94 \pm 1.98$ & $<0.001$ \\
Handedness (L/R) & $0 / 18$ & $0 / 18$ & $>0.05$ \\
Length of illness & $3.79 \pm 2.78$ & - & \\
$\quad$ years) & & & \\
Total brain volume & $1439.41 \pm 47.57$ & $1417.93 \pm 51.19$ & $>0.05$ \\
Pituitary volume & $0.57 \pm 0.24$ & $0.84 \pm 0.20$ & $<0.001$ \\
\hline
\end{tabular}

Volumes presented are in cubic centimeters $\left(\mathrm{cm}^{3}\right)$ 
determined by HDRS scores $(\mathrm{r}=0.17, \mathrm{p}>0.05)$.

\section{DISCUSSION}

This study found a significant reduction of pituitary volumes in the patients with somatization disorder, supported by the ANCOVA predicting pituitary volumes demonstrated a significant main effect of diagnostic group. The obtained differences in pituiatry anatomy could not be considered as a result of group differences in age or in whole brain volume, because smaller volumes were significant in analyses that covaried for these variables. To the best of our knowledge, this is the first report of pituitary volumes in somatization disorder.

It was well established the role of hypothalamic-pituitaryadrenal axis HPA in anxiety and fear. When exposed to any stress factor, hypothalamic $\mathrm{CRH}$ production rises, stimulating the pituitary release of ACTH and finally cortisol secretion by the adrenal cortex. When we deal with the physiological mechanisms in the etiology of somatoform disorders beyond psychological, and social contributions, one of the important contribution comes from the function of the HPA because of the fact that hypocortisolism has been suggested to cause a vulnerability for the occurrence of somatoform symptoms. ${ }^{21,30}$ This possible relationship had led us to consider the association between hypochondriasis and HPA and we had examined pituiatry volumes in twenty individuals with hypochondriasis (ten males, ten females), aged 20 to 48 years, and healthy controls and found significantly smaller pituitary volumes of the whole group of hypochondriac patients compared to healthy controls. ${ }^{11}$ However, in somatization disorder, despite of the its possible physiological relationship with HPA, no volumetric study regarding pituitary volumes has been performed. In our previous study, ${ }^{16}$ we evaluated the hippocampus amygdalar complex which are associated with both stress and regulation of emotion that are main basis clinical presentation of somatization disorder in totally 40 subjects and found that the patients had significantly smaller mean volumes of the left and right amygdala. However, two groups did not differ significantly in terms of whole brain, total gray and white matter or hippocampus volumes. In conclusion, we suggested that the patients with somatization disorder had significantly smaller mean volumes of the left and right amygdala without any differences in regard to whole brain, total gray and white matter or hippocampus volumes. Since the hippocampus and amygdala complex, a glucocorticoid feedback area, is highly sensitive to endogenous glucocorticoid levels and so is an important region affected by stress modulation organized by the hypothalamo-pituitary-adrenal axis (HPA), ${ }^{17-19}$ our findings may be associated with those found in the present study. On the other hand, it was reported that increased HPA activity leading to high cortisol values might affect pituitary volume. ${ }^{19}$ Thus, we consider that dysregulated HPA axis might have affected the pituitary volumes in somatization patients much as pituitary hormones were not evaluated in the present investigation.

Major limitation of the present study was that its sample was small sample size. Secondly, although significant differences were observed with this limited power, replication of the results with larger samples may shed further light on the reliability of these anatomical differences. Third, including only female patients in to the peresent study can prevent the generalizability of the results. Fourth, the comorbidity of depressive disorder could have affected the findings we found in the present study. Fifth, though we did not include the patients who took any psychotropic drug within two weeks The patients had a history of previous following psychotropic treatments, antidepressants $(n=8)$, antipsychotics $(n=5)$ and anxiolytics $(n=10)$, The results might have been affected these drugs' on potential effect on pituitary function. Finally, we should mention about possible selection bias, limitations of the manual tracing method, and absence of the pituitary hormones dosage as an index of the subject's endocrinologic status.

In conclusion, we suggest that the patients with somatization disorder might have significantly smaller pituitary volumes compared to healthy control subjects. On the basis of the current findings, it seems reasonable to evaluate that abnormalities in connectivity and/or metabolism dimensions and to examine the effects of drugs or psychotherapeutic approaches could be especially informative.

\section{Acknowledgments}

We would like to thank to FUBAP (Scientific research and project support unit of Firat University) for financial support and to Ali Saffet Gonul, M.D. for his English editing.

\section{REFERENCES}

1. American Psychiatric Association. Diagnostic and Statistical Manual of Mental Disorders, 4th Edition. Washington DC: American Psychiatric Association Press; 1994.

2. Farley J, Woodruff RA Jr, Guze SB. The prevalence of hysteria and conversion symptoms. Br J Psychiatry 1968;114:1121-1125.

3. deGruy F, Columbia L, Dickinson P. Somatization disorder in a family practice. J Fam Pract 1987;25:45-51.

4. Barsky AJ, Orav EJ, Bates DW. Somatization increases medical utilization and costs independent of psychiatric and medical comorbidity. Arch Gen Psychiatry 2005;62:903-910.

5. Merskey H. The Analysis of Hysteria: Understanding Conversion and Dissociation, 2nd Edition. London: Gaskell; 1995.

6. Katz RJ. Neurobiology of obsessive compulsive disorder--a serotonergic basis of Freudian repression. Neurosci Biobehav Rev 1991;15:375-381.

7. Rief W, Hennings A, Riemer S, Euteneuer F. Psychobiological differences between depression and somatization. J Psychosom Res 2010;68: 495-502.

8. Vuilleumier P, Chicherio C, Assal F, Schwartz S, Slosman D, Landis T. Functional neuroanatomical correlates of hysterical sensorimotor loss. 
Brain 2001;124:1077-1090.

9. Stern DB. Psychogenic Somatic Symptoms on the Left Side: Review and Interpretation. In: Myslobodsky MS, Editor. Hemisyndromes: Psychobiology, Neurology, Psychiatry. New York: Academic Press, 1983, p.415-445.

10. Tiihonen J, Kuikka J, Viinamäki H, Lehtonen J, Partanen J. Altered cerebral blood flow during hysterical paresthesia. Biol Psychiatry 1995;37: 134-135.

11. Spence SA, Crimlisk HL, Cope H, Ron MA, Grasby PM. Discrete neurophysiological correlates in prefrontal cortex during hysterical and feigned disorder of movement. Lancet 2000;355:1243-1244.

12. Lorenz J, Kunze K, Bromm B. Differentiation of conversive sensory loss and malingering by P300 in a modified oddball task. Neuroreport 1998; 9:187-191

13. Flor-Henry P, Fromm-Auch D, Tapper M, Schopflocher D. A neuropsychological study of the stable syndrome of hysteria. Biol Psychiatry 1981;16:601-626.

14. Atmaca M, Aydin A, Tezcan E, Poyraz AK, Kara B. Volumetric investigation of brain regions in patients with conversion disorder. Prog Neuropsychopharmacol Biol Psychiatry 2006;30:708-713.

15. Atmaca M, Sec S, Yildirim H, Kayali A, Korkmaz S. A volumetric MRI analysis of hypochondriac patients. Bull Clin Psychopharmacology; 2010. in press.

16. Atmaca M, Sirlier B, Yildirim H, Kayali A. Hippocampus and amygdalar volumes in patients with somatization disorder. Prog Neuropsychopharmacol Biol Psychiatry 2011;35:1699-1703.

17. Sheline YI, Wang PW, Gado MH, Csernansky JG, Vannier MW. Hippocampal atrophy in recurrent major depression. Proc Natl Acad Sci U S A 1996;93:3908-3913.

18. Hoschl C, Hajek T. Hippocampal damage mediated by corticosteroids--a neuropsychiatric research challenge. Eur Arch Psychiatry Clin Neurosci 2001;251(Suppl 2):II81-II88.

19. Mizoguchi K, Ishige A, Aburada M, Tabira T. Chronic stress attenuates glucocorticoid negative feedback: involvement of the prefrontal cortex and hippocampus. Neuroscience 2003;119:887-897.

20. Barsky AJ, Borus JF. Functional somatic syndromes. Ann Intern Med 1999;130:910-921.

21. Ehlert U, Gaab J, Heinrichs M. Psychoneuroendocrinological contributions to the etiology of depression, posttraumatic stress disorder, and stress-related bodily disorders: the role of the hypothalamus-pituitaryadrenal axis. Biol Psychol 2001;57:141-152.

22. Altemus M, Pigott T, Kalogeras KT, Demitrack M, Dubbert B, Murphy $\mathrm{DL}$, et al. Abnormalities in the regulation of vasopressin and corticotropin releasing factor secretion in obsessive-compulsive disorder. Arch Gen Psychiatry 1992;49:9-20.

23. Corapçıoğlu A, Aydemir O, Yıldız M, Esen A, Koroglu E. DSM-IV Eksen I Bozuklukları (SCID-I) İçin Yapılandırılmış Klinik Görüşme, Klinik Versiyon. Ankara: Hekimler Yayın Birliği; 1999.

24. Hamilton M. A rating scale for depression. J Neurol Neurosurg Psychiatry 1960;23:56-62.

25. Talairach J, Tournoux P. Coplanar Stereotaxic Atlas of the Human Brain. New York: Thieme Medical Publishers; 1998.

26. Daniels DL, Haughton VM, Naidich TP. Cranial and Spinal Magnetic Resonance Imaging an Atlas and Guide. New York: Raven Press; 1987.

27. Sassi RB, Nicoletti M, Brambilla P, Harenski K, Mallinger AG, Frank E, et al. Decreased pituitary volume in patients with bipolar disorder. Biol Psychiatry 2001;50:271-280.

28. Thomas LA, De Bellis MD. Pituitary volumes in pediatric maltreatment-related posttraumatic stress disorder. Biol Psychiatry 2004;55: 752-758.

29. MacMaster FP, Kusumakar V. MRI study of the pituitary gland in adolescent depression. J Psychiatr Res 2004;38:231-236.

30. Heim C, Ehlert J, Hellhammer DH. The potential role of hypocortisolism in the pathophysiology of stress-related bodily disorders. Psychoneuroendocrinology 2000;25:1-35. 